\title{
Antioxidant Activities of Extracts Prepared from Sweet Potatoes with Different Flesh Colors
}

\author{
Dong Chung Kim - Chikwang Kim - Man-Jin In*
}

\section{육질색 종류별 고구마 추출물의 항산화 활성}

김동청 - 김재광 · 인만진*

Received: 29 August 2014 / Accepted: 1 October 2014 / Published Online: 31 March 2015

(C) The Korean Society for Applied Biological Chemistry 2015

\begin{abstract}
Antioxidant activities of ethanol extracts from three types of sweet potatoes with distinctive flesh color (white, orange, and purple) were investigated. Total phenolic content of purplefleshed sweet potato (PF) was always 2- to 5-fold higher than those of white-fleshed (WF) and orange-fleshed sweet potato (OF). 2,2-diphenyl-1-picryl-hydrazyl free radical scavenging activity of $70 \%$ ethanol extracts was highest $\left(\mathrm{EC}_{50}=0.179 \mathrm{mg} / \mathrm{mL}\right)$ for $\mathrm{PF}$ and lowest $\left(\mathrm{EC}_{50}=2.127 \mathrm{mg} / \mathrm{mL}\right)$ for $\mathrm{OF}$. And then, reducing power was also highest $\left(\mathrm{EC}_{50}=0.236 \mathrm{mg} / \mathrm{mL}\right)$ for PF and lowest $\left(\mathrm{EC}_{50}=1.587 \mathrm{mg} / \mathrm{mL}\right)$ for WF. Antioxidant activities of $70 \%$ ethanol extracts were closely related to the amount of total phenolics. These results imply that antioxidant activity of PF is 6.7 to 11.9 times higher than those of WF and OF.
\end{abstract}

Keywords antioxidant activity - ethanol extract $\cdot$ sweet potato $\cdot$ total phenolic

D. C. Kim $\cdot$ M.-J. In

Department of Human Nutrition and Food Science, Chungwoon University, Hongseong 350-701, Republic of Korea

\section{Kim}

Department of Hotel Culinary and Catering Management, Chungwoon University, Hongseong 350-701, Republic of Korea

*Corresponding author (M.-J. In: manjin@chungwoon.ac.kr)

This is an Open Access article distributed under the terms of the Creative Commons Attribution Non-Commercial License (http://creativecommons. org/licenses/by-nc/3.0/) which permits unrestricted non-commercial use, distribution, and reproduction in any medium, provided the original work is properly cited.
세계적으로 중요한 식량작물 중 하나인 고구마(Ipomoea batatas L.)는 대부분 아시아와 아프리카 지역에서 재배되고 있으며, 우 리나라에서도 2013 년에는 약 $22,000 \mathrm{ha}$ 에서 약 33 만톤이 생산 되었다. 고구마는 수분이 $70 \%$ 이며 고형분 중 $75 \%$ 이상이 탄 수화물로 구성되어 식량작물로 중요할 뿐만 아니라, 식이섬유, 무기질과 비타민 등을 다량 함유하고 있어 영양학적으로도 우 수한 식품이다(Ravindran 등, 1995). 고구마의 전분은 오래 전 부터 당면의 원료로, 최근에는 바이오에탄올, 소주, 물엿, 장류, 의약품 등의 원료로도 사용되고 있다(Ziska 등, 2009; Park 등, 2010). 그러나 고구마의 대부분은 찐고구마, 군고구마, 튀김과 같은 단순가공품 및 생식용으로 소비되고 있다(Lee 등, 2006). 최근에는 고구마에 함유된 $\beta$-카로틴, 안토시아닌, 폴리페놀, 강 글리오사이드 등과 같은 성분의 기능성이 알려지고(Almeida와 Penteado, 1988; Lee 등, 2000; Lee 등, 2007), 기능성을 향상 시킨 새로운 유색 고구마 품종이 개발되어 대량생산되면서 고 구마가 건강기능식품의 소재로 새롭게 인식되고 있다(Yoshimoto, 2001). 육질이 신선한 오렌지색을 보이는 주황색고구마는 일반 고구마에 비하여 천연 $\beta$-카로틴 함량이 매우 높기 때문에 레티 놀의 공급원, 항암효과를 갖는 식품으로 인식되며(Peto 등, 1984; Almeida와 Penteado, 1988; Teow 등, 2007), 표피와 육 질이 진한 자색을 띠는 자색고구마는 높은 안토시아닌 함량에 의한 항돌연변이, 항산화, 간기능 보호 등의 기능이 보고되어 있다(Choi 등, 2003; Lee 등, 2007; Park 등, 2011). 특히 고 구마의 항산화 활성에 관한 연구로는 항산화 활성을 보이는 페 놀화합물의 분리(Lee 등, 2000 ; Lee 등, 2007), 잎과 잎자루의 항산화 활성(Ahn 등, 2009; Li 등, 2012), 재배조건에 따른 황 산화 활성(Woo 등, 2012), 건조방법과 조리방법이 항산화 활성 에 미치는 영향(Yang 등, 2010; Lee, 등 2012) 등이 보고되어 있다. 또한 고구마 품종별 항산화성에 관한 연구가 보고(Lee 등, 1999; Song 등, 2005; Lee 등, 2007)되어 있으나 식품용으 로 사용할 수 없는 메탄올, ethyl acetate와 같은 용매를 추출물 제조에 활용하였거나, 에탄올을 용매로 제조한 추출물에는 고구 
마 품종 간의 항산화 활성이 다소 정성적으로 기술되어 정량적 인 비교는 곤란한 형편이다. 따라서 본 연구에서는 육질색이 상 이한 고구마로부터 에탄올 추출물을 제조하여 폴리페놀 화합물 의 함량을 분석하고, 라디칼 소거 활성과 환원력의 차이를 정 량적으로 비교하여 고구마의 항산화 활성에 관한 기존의 결과 (Lee 등, 1999; Lee 등, 2007)를 보완함으로써 건강기능식품의 소재로 고구마의 활용도 향상에 기여하고자 하였다.

본 실험에 사용한 고구마는 2013년에 생산된 것으로 일반 고 구마(white-fleshed sweet potato; WF)와 유색고구마로 주황색고 구마(orange-fleshed sweet potato; OF)와 자색고구마(purplefleshed sweet potato; PF)를 시중에서 구입하여 사용하였다. 고 구마 식용부위를 동결건조 한 다음 분쇄하여 $100 ~ 300 \mu \mathrm{m}$ 크기 의 분말을 제조하였다. 고구마 분말의 10 배의 에탄올을 추출용 매로 항온 진탕조에서 2시간 동안 진탕하여 추출물을 제조하였 다. 추출된 용액은 원심분리하고 $\left(1,000 \times \mathrm{g}, 4^{\circ} \mathrm{C}, 15\right.$ 분 $)$ 감압농축 하여 용매를 제거하고 건조하여 추출 수율을 계산하였다. 고구 마 추출물의 총 폴리페놀 화합물 함량은 Folin-Ciocalteu 시약 이 폴리페놀 화합물에 의하여 환원되어 몰리브덴 청색으로 발 색되는 원리를 이용한 방법(Folin과 Denis, 1912)으로 표준물질 로 gallic acid를 사용하여 측정하였으며, 추출물 고형분 $\mathrm{mg}$ 당 $\mu \mathrm{g}$ gallic acid equivalent (GAE)로 표시하였다. 에탄올 농도에 따른 추출 수율을 조사한 결과(Table 1), 고구마 육질색에 따른 추출 수율은 매우 유사하였다. 또한 에탄올의 농도가 0 에서 $70 \%$ 까지 증가됨에 따라 수율이 서서히 감소되며(약 $29 \% \rightarrow$ 약 $16 \%$ ) 에탄올 $100 \%$ 에서 매우 낮은 수율 $(2 \sim 3 \%)$ 을 보이는 경향 도 동일하였다. 에탄올 $70 \%$ 이상에서 $\mathrm{OF}$ 의 수율이 가장 높은 것은 $\mathrm{OF}$ 의 높은 지용성 색소( $\beta$-carotene) 함량에 기인하며(Teow 등, 2007), 메탄올 또는 $80 \%$ 에탄올을 용매로 사용한 기존의 연구결과(Park 등, 2011; Lee 등, 2012)와 동일한 경향이었다. 에탄올 농도에 따른 총 폴리페놀 화합물 함량은 $\mathrm{PF}>\mathrm{WF}>\mathrm{OF}$ 의 순이며, 모든 농도에서 $\mathrm{PF}$ 가 $\mathrm{WF}, \mathrm{OF}$ 보다 2 배 이상 높은 값을 보였다(Table 1). 이는 PF에 다량 함유된 anthocyanin 색 소에 기인하며, 자색고구마의 총 페놀함량이 주황색고구마와 일 반고구마에 비하여 높다는 보고(Lee 등, 2007; Park 등, 2011; Lee 등, 2012)와 같은 경향이다. 폴리페놀 함량의 순서가 PF> $\mathrm{OF}>\mathrm{WF}$ 라는 보고(Song 등, 2005)와 상이한 것은 고구마 품종 에 따라 백색계열의 고구마도 황색고구마 수준의 총 폴리페놀 함량을 나타낸다는 결과(Park 등, 2011)를 고려하면 품종의 차 이와 추출조건의 차이에 기인하는 것으로 사료되었다. $\mathrm{PF}$ 는 $50 \sim 70 \%$ 에탄올 추출물 $(74.1 \mu \mathrm{g} \mathrm{GAE} / \mathrm{mg}$ extract)에서, $\mathrm{WF}$ 와 $\mathrm{OF}$ 는 $70 \%$ 에탄올 추출물(32.8과 $21.5 \mu \mathrm{g} \mathrm{GAE} / \mathrm{mg}$ extract)에서 가장 높은 총 폴리페놀 함량을 보였으며, 폴리페놀 성분은 식물 에 널리 분포하는 이차 대사물로 구조적으로 phenolic hydroxyl 기가 존재하므로 항산화성을 나타내는 것으로 알려져 있으므로 (Lee 등, 1999; Lee 등, 2000; Amin과 Yazdnparast, 2007)
$\mathrm{WF}, \mathrm{OF}, \mathrm{PF}$ 의 $70 \%$ 에탄올 추출물을 항산화 활성 비교에 이용 하였다.

체내에서 생성되는 유리 radical은 반응성이 강한 화학종으로 지방, 단백질, 핵산 등 생체 구성요소에 산화적 손상을 유발하 고 돌연변이, 암, 고혈압, 류머티즘 등 만성질환의 원인이 되기 도 한다(Yen과 Chen, 1995). 본 연구에서도 $\mathrm{WF}, \mathrm{OF}, \mathrm{PF}$ 의 $70 \%$ 에탄올 추출물의 항산화 활성을 2,2-diphenyl-1-picrylhydrazyl (DPPH) radical의 소거활성(Blois, 1958)으로 비교하였 다. 그 결과(Fig. $1 \mathrm{~A}), \mathrm{WF}, \mathrm{OF}, \mathrm{PF}$ 공히 추출물의 농도 증가 에 비례하여 소거활성은 증가하였고, $\mathrm{PF}$ 의 활성이 $\mathrm{WF}$ 와 $\mathrm{OF}$ 보 다 월등하게 우수하였으며 이는 총 폴리페놀 화합물 함량차이 에 기인하는 것으로 판단되었다. 또한 $\mathrm{WF}$ 와 $\mathrm{OF}$ 의 radical 소 거활성은 거의 유사한 경향을 보였으며, 이러한 현상은 자색고 구마 $85.2 \%$, 일반 고구마 $35.7 \%$, 황색고구마 $36.3 \%$ 의 소거활 성을 보인다는 보고(Song 등, 2005)와 일치하는 경향이었다. $\mathrm{DPPH}$ radical 절반의 소거활성을 나타내는 $\mathrm{EC}_{50}$ 을 비교하면 (Table 2) WF는 $2.030 \mathrm{mg} / \mathrm{mL}, \mathrm{OF}$ 는 $2.127 \mathrm{mg} / \mathrm{mL}, \mathrm{PF}$ 는 0.179 $\mathrm{mg} / \mathrm{mL}$ 로 계산되었으며, 이는 추출물의 폴리페놀 함량과 일치

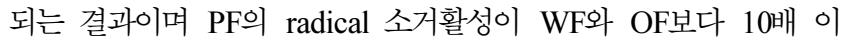
상 우수하였다. $\mathrm{EC}_{50}$ 으로 비교하면 $\mathrm{PF}$ 의 radical 소거활성은 고

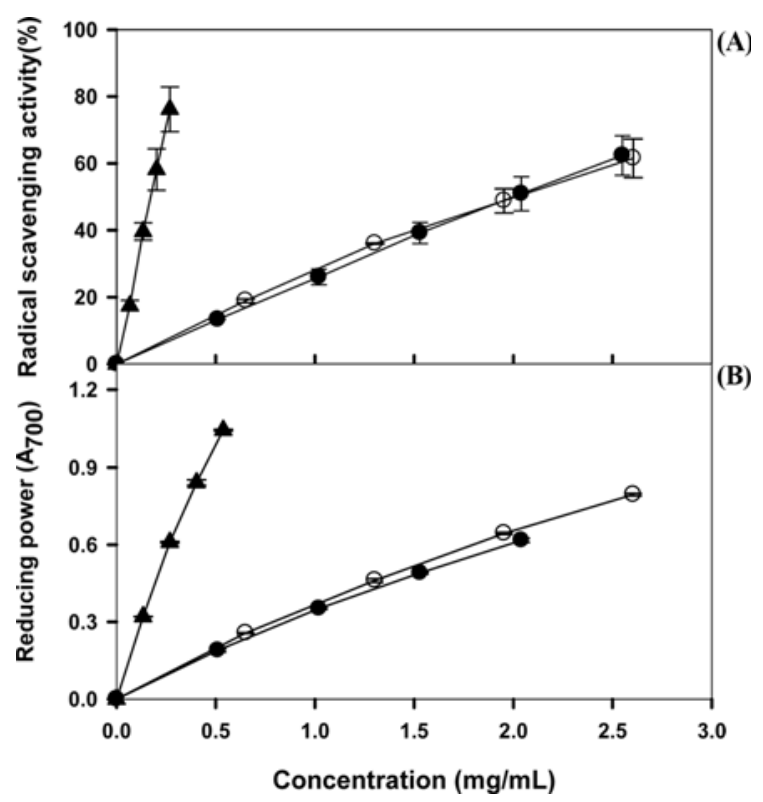

Fig. 1 DPPH radical scavenging activity (panel A) and reducing power (panel B) of $70 \%$ ethanol extract of white-fleshed sweet potato (closed circle), orange-fleshed sweet potato (open circle), and purple-fleshed sweet potato (closed triangle). Data were means and SD of triplicate measurements.

Table 1 Content of total phenolic and yield of sweet potato extracts prepared with different ethanol concentration

\begin{tabular}{|c|c|c|c|c|c|c|c|c|c|c|}
\hline \multirow{2}{*}{ Flesh color } & \multicolumn{5}{|c|}{ Yield (\%) } & \multicolumn{5}{|c|}{ Total phenolic ${ }^{1)}$} \\
\hline & $0 \%{ }^{2)}$ & $30 \%$ & $50 \%$ & $70 \%$ & $100 \%$ & $0 \%$ & $30 \%$ & $50 \%$ & $70 \%$ & $100 \%$ \\
\hline White & 29.22 & 26.07 & 23.04 & 17.83 & 1.59 & 18.50 & 15.22 & 16.76 & 32.75 & 10.48 \\
\hline Orange & 29.13 & 22.94 & 21.37 & 19.78 & 2.98 & 17.60 & 21.17 & 16.19 & 21.51 & 3.63 \\
\hline Purple & 25.04 & 22.11 & 19.07 & 16.37 & 2.29 & 49.50 & 63.00 & 74.15 & 74.05 & 19.59 \\
\hline
\end{tabular}

${ }^{1)} \mu \mathrm{g}$ gallic acid equivalent (GAE)/mg solid in extract.

${ }^{2)}$ Ethanol concentration. 
Table $2 \mathrm{EC}_{50}$ values of $70 \%$ ethanol extracts prepared from sweet potato with different flesh colors

\begin{tabular}{ccc}
\hline & \multicolumn{2}{c}{$\mathrm{EC}_{50}$ values $^{1)}(\mathrm{mg} / \mathrm{mL})$ of antioxidant activities } \\
\cline { 2 - 3 } & Radical scavenging activity & Reducing power \\
\hline White & $2.030 \pm 0.191^{2)}$ & $1.587 \pm 0.020$ \\
Orange & $2.127 \pm 0.179$ & $1.524 \pm 0.010$ \\
Purple & $0.179 \pm 0.016$ & $0.236 \pm 0.002$
\end{tabular}

${ }^{1)} \mathrm{EC}_{50}$ values are expressed as the effective concentration at which antioxidant activity using DPPH radical was scavenged by $50 \%$; absorbance was 0.5 for reducing power.

${ }^{2)}$ Values are means $\pm \operatorname{SD}(\mathrm{n}=3)$.

구마 잎 $80 \%$ 에탄올 추출물 $(\mathrm{Li}$ 등, 2012)과 매우 비슷하며, 복 분자 $60 \%$ acetone 추출물(Jun 등, 2014)보다 4.5배 우수하였다. $\mathrm{Oyaizu}(1986)$ 의 방법에 따라 $\mathrm{WF}, \mathrm{OF}, \mathrm{PF}$ 추출물의 항산화 활 성을 환원력으로 측정하였다. 환원력은 ferri-ferricyanide $\left(\mathrm{Fe}^{3+}\right)$ 혼합물이 수소를 공여하여 유리 radical을 안정화시켜 ferrous $\left(\mathrm{Fe}^{2+}\right)$ 로 전환시키는 능력을 흡광도 값으로 나타낸 것으로 항산 화 작용의 여러 기작 중 활성 산소종 및 유리기에 전자를 공여 하는 능력을 검증하는 방법이다. 환원력이 강할수록 높은 흡광 도 값을 나타낸다. 측정 결과(Fig. 1B), DPPH radical 소거활성 과 동일하게 $\mathrm{WF}, \mathrm{OF}, \mathrm{PF}$ 공히 추출물의 농도 증가에 비례하 여 환원력은 증가하였고, $\mathrm{PF}$ 의 활성이 $\mathrm{WF}$ 와 $\mathrm{OF}$ 보다 월등하게 우수하였다. 이는 쇠비름 추출물의 결과(Kwon 등, 2014)와 동 일하게 각 추출물에 함유된 총 폴리페놀에 의한 것으로 사료되 었다. 반응액의 흡광도가 0.5 가 되는데 필요한 시료의 농도를 나타내는 $\mathrm{EC}_{50}$ 을 비교하면(Table 2), $\mathrm{WF}$ 는 $1.587 \mathrm{mg} / \mathrm{mL}, \mathrm{OF}$ 는 $1.524 \mathrm{mg} / \mathrm{mL}, \mathrm{PF}$ 는 $0.236 \mathrm{mg} / \mathrm{mL}$ 로 계산되어, $\mathrm{WF}$ 와 $\mathrm{OF}$ 의 환원력은 거의 유사하였고 $\mathrm{PF}$ 의 환원력이 $\mathrm{WF}$ 와 $\mathrm{OF}$ 보다 6 배 이상 우수하였다. 또한 $\mathrm{PF} 70 \%$ 에탄올 추출물은 복분자 $60 \%$ acetone 추출물(Jun 등, 2014)보다 약 3.7배 낮은 $\mathrm{EC}_{50}$ 값을 보 여 강한 항산화 활성을 갖는 것으로 나타났다.

이상의 결과로부터 자색고구마는 다른 고구마에 비하여 2 배 이상의 폴리페놀 화합물을 함유하고 있으며, 항산화 활성도 radical 소거활성은 10 배, 환원력은 6 배 이상 우수한 것을 확인 할 수 있었다. 또한 고구마에서 총 폴리페놀 함량이 항산화 활 성의 지표라는 기존의 결과(Teow 등, 2007)와도 잘 일치하였다.

\section{초 록}

육질색에 따른 일반고구마(WF), 주황색고구마(OF), 자색고구마 $(\mathrm{PF})$ 를 동결건조 후 에탄올 농도를 달리하여 추출물을 제조하 고 분석하였다. 고구마 육질색과 에탄올 농도에 따른 추출 수 율은 매우 유사하였다. 에탄올의 농도가 $0 \%$ 에서 $70 \%$ 까지 증가 됨에 따라 추출 수율이 서서히 감소되었으며, 에탄올 $100 \%$ 에서 매우 낮은 추출 수율 $(2 \sim 3 \%)$ 을 보였다. 총 폴리페놀 화합물 함량 은 $\mathrm{PF}$ 가 $\mathrm{WF}, \mathrm{OF}$ 보다 2 5배 높은 값을 보였다. 총 폴리페놀 화 합물 함량이 가장 높은 $70 \%$ 에탄올 추출물에서 2,2-diphenyl-1picryl-hydrazyl 유리 radical 소거활성의 $\mathrm{EC}_{50}$ 은 WF $2.030 \mathrm{mg} /$ $\mathrm{mL}, \mathrm{OF} 2.127 \mathrm{mg} / \mathrm{mL}, \mathrm{PF} \quad 0.179 \mathrm{mg} / \mathrm{mL}$, 환원력의 $\mathrm{EC}_{50}$ 은 WF $1.587 \mathrm{mg} / \mathrm{mL}$, OF $1.524 \mathrm{mg} / \mathrm{mL}$, PF $0.236 \mathrm{mg} / \mathrm{mL}$ 이었다. 추출물의 항산화 활성은 총 폴리페놀 함량과 상관관계를 갖는
것으로 나타났다. 따라서, $\mathrm{PF}$ 의 황산화 활성은 $\mathrm{WF}$ 와 $\mathrm{OF}$ 에 비 하여 radical 소거활성은 10 배, 환원력은 6 배 이상 우수하였다.

Keywords 고구마·에탄올 추출물 - 폴리페놀 - 항산화 활성

\section{References}

Ahn YO, Kim SH, Lee HS, Lee JS, Ma D, and Kwak SS (2009) Contents of low molecular weight antioxidants in the leaves of different sweet potato cultivars at harvest. J Plant Biotechnol 36, 214-8.

Almeida LB and Penteado MVC (1988) Carotenoids and pro-vitamin A value of white fleshed Brazilian sweet potatoes (Ipomoea batatas Lam.) $J$ Food Comp Anal 4, 341-52.

Amin A and Yazdnparast R (2007) Antioxidant and free radical scavenging potential of Achillea santolina extracts. Food Chem 104, 21-9.

Blois MS (1958) Antioxidant determination by the use of a stable free radical. Nature 181, 1199-200.

Choi YJ, Kim HA, Bang MA, Oh YB, Jeong BC, Moon YH et al. (2003) Protective effect of purple sweet potato (Ipomoea batatas) on hepatotoxicity rats induced carbon tetrachloride. Korean J Food Culture 18, 202-10.

Folin O and Denis W (1912) On phosphotungstic-phosphomolybdic compounds as color reagents. $J$ Biol Chem 12, 239-43.

Jun HI, Kim Ya, and Kim YS (2014) Antioxidant activities of Rubus coreanus Miguel and Morus alba L. fruits. J Korean Soc Food Sci Nutr 43, 381-8.

Kwon YR, Cho SM, Hwang SP, Kwon GM, Kim JW, and Youn KS (2014) Antioxidant, physiological activities, and acetylcholinesterase inhibitory activity of Portulaca oleracea extracts with different extraction methods. J Korean Soc Food Sci Nutr 43, 389-96.

Lee GH, Kwon BK, Yim SY, and Oh MJ (2000) Phenolic compounds in sweet potatoes and their antioxidative activity. Korean J Postharvest Sci Technol 7, 331-6.

Lee HH, Kang SG, and Rhim JW (1999) Characteristics of antioxidative and antimicrobial activities of various cultivars of sweet potato. Korean $J$ Food Sci Technol 31, 1090-5.

Lee JS, Ahn YS, Kim HS, Chung MN, and Jeong BC (2006) Making techniques of high quality powder in sweet potato. Korean J Crop Sci 51, 198-203.

Lee JS, Ahn YS, Kim HS, Chung MN, and Kim HS (2007) Biological activity of varieties, isolation and purification of antioxidants compounds in sweet potato. Korean J Breed Sci 39, 296-301.

Lee YM, Bae JH, Kim JB, Kim SY, Chung MN, Park MY et al. (2012) Changes in the physiological activities of four sweet potato varieties by cooking condition. Korean J Nutr 45, 12-9.

Li M, Jang GY, Lee SH, Woo KS, Sin HM, Kim HS et al. (2012) Chemical compositions and antioxidant activities of leaves and stalks from different sweet potato cultivars. J Korean Soc Food Sci Nutr 41, 165662.

Oyaizu M (1986) Studies on products of browning reaction: Antioxidant activities of products of browning reaction prepared from glucosamine. Jap J Nutr 44, 307-15.

Park JS, Bae JO, Choi GH, Chung BW, and Choi DS (2011) Antimutagenicity of Korean sweet potato (Ipomoea batatas L.) cultivars. $J$ Korean Soc Food Sci Nutr 40, 37-46.

Park JS, Chung BW, Bae CJ, Lee JH, Jung MY, and Choi DS (2010) Effects of sweet potato cultivars and koji types on general properties and volatile flavor compounds in sweet potato soju. Korean J Food Sci Technol 42, 468-74.

Peto R, Coll R, Buckey JD, and Sporn MB (1984) Can dietary $\beta$-carotene materially reduce human cancer rates? Nature 290-201-8.

Ravindran V, Ravindran G, Sirakanesan R, and Rajaguru SB (1995) Biochemical and nutritional assessment of tubers from 16 cultivars of sweet potato. J Agric Food Chem 43, 2646-51.

Song J, Chung MN, Kim JT, Chi HY, and Son JR (2005) Quality characteristics and antioxidative activities in various cultivars of sweet 
potato. Korean J Crop Sci 50, 141-6.

Teow CC, Truong V, McFeeters RF, Thompson RL, Pecoto KV, and Yencho GC (2007) Antioxidant activities, phenolic and $\beta$-carotene contents of sweet potato genotypes with varying flesh colours. Food Chem 103, 829-38.

Woo KS, Seo HI, Lee YH, Lim HY, Ko JY, Song SB et al. (2012) Antioxidant compounds and antioxidant activities of sweet potatoes with cultivated conditions. J Korean Soc Food Sci Nutr 41, 519-25.

Yang J, Chen JF, Zhao YY, and Mao LC (2010) Effects of drying processes on the antioxidant properties in sweet potatoes. Agric Sci China 9, 1522-
9.

Yen GC and Chen HY (1995) Antioxidant activity of various tea extracts in relation to their antimutagenicity. J Agric Food Chem 43, 27-32.

Yoshimoto M (2001) New trends of processing and use of sweet potato in Japan. Farming Jpn 35, 22-8.

Ziska LH, Runion GB, Tomecek M, Prior SA, Torbet HA, and Sicher R (2009) An evaluation of cassava, sweet potato and field corn as potential carbohydrate sources for bioethanol production in Alabama and Maryland. Biomass Bioenergy 33, 1503-8. 